\title{
Acute Marijuana Effects on Human Risk Taking
}

\author{
Scott D Lane, ${ }^{*, 1,2}$, Don R Cherek ${ }^{1,2}$, Oleg V Tcheremissine', Lori M Lieving' and Cythia J Pietras' \\ 'Department of Psychiatry \& Behavioral Sciences, University of Texas Health Science Center, Houston, TX, USA; ${ }^{2}$ Graduate School of Biomedical \\ Science, University of Texas Health Science Center, Houston, TX, USA
}

Previous studies have established a relationship between marijuana use and risky behavior in natural settings. A limited number of laboratory investigations of marijuana effects on human risk taking have been conducted. The present study was designed to examine the acute effects of smoked marijuana on human risk taking, and to identify behavioral mechanisms that may be involved in drug-induced changes in the probability of risky behavior. Using a laboratory measure of risk taking designed to address acute drug effects, 10 adults were administered placebo cigarettes and three doses of active marijuana cigarettes (half placebo and half I.77\%; ।.77\%; and 3.58\% $\Delta^{9}$ $\mathrm{THC}$ ) in a within-subject repeated-measures experimental design. The risk-taking task presented subjects with a choice between two response options operationally defined as risky and nonrisky. Data analyses examined cardiovascular and subjective effects, response rates, distribution of choices between the risky and nonrisky option, and first-order transition probabilities of trial-by-trial data. The 3.58\% $\mathrm{THC}$ dose increased selection of the risky response option, and uniquely shifted response probabilities following both winning and losing outcomes following selection of the risky option. Acute marijuana administration thereby produced measurable changes in risky decision making under laboratory conditions. Consistent with previous risk-taking studies, shifts in trial-by-trial response probabilities at the highest dose suggested a change in sensitivity to both reinforced and losing risky outcomes. Altered sensitivity to consequences may be a mechanism in drug-induced changes in risk taking. Possible neurobiological sites of action related to THC are discussed. Neuropsychopharmacology (2005) 30, 800-809. doi:I0. I038/sj.npp. 1300620

Keywords: marijuana; risk taking; decision making; humans; laboratory experiment; $\Delta^{9}$-THC

\section{INTRODUCTION}

Ample evidence supports the existence of a relationship between marijuana use and risk-taking behavior. Adlaf and Smart (1983) found risk scores on a scale that measured a battery of risky behaviors were significantly higher for regular marijuana users than nonusers. A survey of instances of negative consequences resulting from marijuana intoxication (with several items relating to risk taking, for example, physical injury, arrest, driving accidents) found that incidence of these items was related to frequency of marijuana use (Cunningham et al, 2000). Early-onset marijuana use is related to later delinquency, having multiple sexual partners, and use of other drugs (Brook et al, 1999). Marijuana use is associated with criminal behavior, notably attempted homicide, drug trafficking, and delinquency in adolescents and young adults (Fergusson and Horwood, 1997; Friedman et al, 2001; Watts and

\footnotetext{
* Correspondence: Dr SD Lane, Department of Psychiatry \& Behavioral Sciences, University of Texas Health Science Center - Houston, 1300 Moursund St., Houston, TX 77030, USA, Tel: + I 713500 2620, Fax: + I 7I3 500 26|8, E-mail: scott.d.lane@uth.tmc.edu

Received 3 May 2004; revised 5 October 2004; accepted 12 October 2004

Online publication: 19 October 2004 at http://www.acnp.org/citations/ NPPI0190404021 I/default/pdf
}

Wright, 1990; White, 1991). Marijuana use has been associated with risky sexual behavior (Duncan et al, 1999; Kingree et al, 2000; Kingree and Betz, 2003; Staton et al, 1999) and chronic use may serve as a predictor for HIV risk (Malow et al, 2001). Marijuana is the most frequently used illicit drug implicated in intoxicated driving (Brookoff $e t a l$, 1994; Moskowitz, 1985; Walsh and Mann, 1999). After alcohol, marijuana accounts for the largest percentage of drug-positive motor vehicle crashes and fatalities (Soderstrom et al, 1995; Stoduto et al, 1993), and THC blood levels indicating recent use are related to increased risk of a car crash (Ramaekers et al, 2004).

Despite the abundance of epidemiological and correlational data, it remains unknown whether acute marijuana intoxication directly affects risk taking. Few experiments have examined this issue under controlled laboratory conditions. The relevant laboratory studies that have been conducted have uniformly focused on performance under driving or flying simulations. These experiments demonstrated that acute marijuana administration impairs performance, and such impairments may be related to both psychomotor function and increased risky maneuvers/ decision making (Hansteen et al, 1976; Janowsky et al, 1976; Liguori et al, 1998, 2002; Ramaekers et al, 2000). Laboratory studies have revealed acute marijuana effects on behaviors, which may be related to risk taking, such as 
aggression (Cherek et al, 1993), impulsivity as measured by the ability to inhibit a signaled, rapid response pattern (McDonald et al, 2003), and complex decision making (Schaefer et al, 1977; Curran et al, 2002). These findings lend indirect support to the hypothesis that marijuana may have direct pharmacological effects on risky behavior. Notably, THC did not alter performance on a probability discounting task, which shares procedural elements with risky decision-making procedures (McDonald et al, 2003).

Variables known to affect the probability of risk taking include the context in which the decision is made; individual personality traits such as sensation-seeking and motivation level; whether outcomes of individual decisions are real or hypothetical; whether or not outcome probabilities are known or uncertain at the time of the decision (risk-taking increases when probabilities are unknown); and sensitivity to outcomes (eg reinforcing and aversive consequences) (Kahneman and Tversky, 1984; Lopes, 1987; Miller and Byrnes, 1997; Rachlin, 1990; Rachlin et al, 1986; Slovic, 1969; Zuckerman, 1979). As risk taking encompasses such a broad array of possible behaviors, it can be difficult to measure accurately under laboratory conditions without a working operational definition. Herein, we refer to risk taking as a class of behaviors with the following parameters: (a) a choice made between two or more options when (b) one of those options has some probability $>0$ of producing (on any given occasion) either a reinforcing or an aversive consequence, and (c) the probability of that aversive consequence is unknown at the time the risky option is chosen. This operational definition is consistent with several theories and definitions of risk taking (Byrnes, 1998; Luce, 1967; Rachlin et al, 1986; Shafir and Tversky, 1995), and encompasses the maladaptive properties of risk taking. Decision theorists have noted important distinctions when the decision maker has complete $v s$ incomplete information about the available choices, for example, whether or not outcome probabilities are known (Byrnes, 1998; Hastie and Dawes, 2001). Part c of the definition thus highlights an important aspect of the procedure: one intended to best model the naturalistic settings in which maladaptive risk-taking behavior occurs.

In previous studies, we have employed a risk-taking task based on the above operational definition. These studies have demonstrated dose-dependent acute alcohol effects on risk taking (Lane et al, 2004), and significant differences between control subjects and subjects with histories of excessive high-risk behavior (Lane and Cherek, 2000, 2001). In each of these studies, trial-by-trial analyses revealed that increased risk taking was related to a reorganization in patterns of decision making following risky responses that resulted in monetary gains or losses. We interpreted these outcomes as representing drug-related changes in sensitivity to reinforcing and aversive consequences (eg gains and losses).

Importantly, $\Delta^{9}$-THC may alter sensitivity to reinforcing consequences (Galbicka et al, 1980; Foltin et al, 1989; Lane and Cherek, 2002; Pihl and Sigal, 1978; Schulze et al, 1989). This phenomenon may be related to the action of $\Delta^{9}$-THC on dopamine neurons in the mesolimbic and mesocortical systems (Gardner and Vorel, 1998; Tanda and Goldberg, 2003; Tanda et al, 1997), disruption of functions in the prefrontal cortex (Pistis et al, 2002; Loeber and Yurgelun-
Todd, 1999; O’Leary et al, 2002; Volkow et al, 1996), or perhaps an interaction between these convergent structures. Importantly, these same regions are activated in human risky decision making (Breiter et al, 2001; Paulus et al, 2001; Matthews et al, 2004). The convergence of data among epidemiological, psychopharmacological, and neurobiological studies suggests that marijuana may have direct pharmacological effects on risk taking. Using an experimental approach to measure risk taking under laboratory conditions, we examined this hypothesis in adult human subjects.

\section{METHOD}

\section{Subjects}

A total of 10 adults (five males, five females), averaging 24.5 years old (range 19-38 years), participated after providing an informed consent approved by the local Institutional Review Board. All subjects reported occasional marijuana use defined as two to 12 times per month, as well as past (but not current) use of at least one other drug, including alcohol, cocaine, opiates, and benzodiazepines. Subjects were recruited via local newspaper advertisements for 'behavioral research'. Based on information obtained during initial telephone interviews, potential subjects were brought to the laboratory for more extensive interviews covering physical and mental health status, and drug and alcohol use history. Exclusion criteria included: (a) current or past medical problems (eg traumatic head injury, asthma, diabetes); (b) current use of any medications; (c) current illicit drug use (except marijuana); and (d) current or past history of an Axis I disorder other than substance dependence, as defined by the Structured Clinical Interview for the DSM-IV (SCID-I, version 2.0, First et al, 1996). One subject met DSM-IV criteria for conduct disorder prior to age 15 years and adult antisocial personality disorder. Four subjects met the criteria for past abuse of alcohol, cocaine, and marijuana. Three of these four subjects met the criteria for past substance dependence: one for marijuana and cocaine; one for alcohol and cocaine; and one for marijuana only. Post hoc analysis showed that these characteristics were unrelated to the physiological, subjective, or behavioral effects of marijuana.

Subjects who reported an average marijuana use of two to 12 times per month during a phone screen were recruited into the study. During the intake interview subjects reported an average of 7.4 uses $(\mathrm{SEM}=1.35$, range $=1-14)$ in the previous 30 days. Prior to administration of the first placebo cigarette, all subjects were required to provide a clean urine sample. Following each active dose, a clean urine sample was required before the next active dose was administered. Urine samples were obtained each morning from subjects who visited the laboratory (3 days per week) at $\approx 0815$. Urine drug screen analysis was carried out using enzyme multiple immunoassay (EMIT d.a.u (R)-SYVA/ Dade Behring Corp). A clean urine sample was operationally defined as having a cannabinoid value below $50 \mathrm{ng} / \mathrm{ml}$, which is the cutoff point used by this assay technique. Any positive cannabinoid test $(>50 \mathrm{ng} / \mathrm{ml})$ was subsequently quantified by thin-layer gas chromatography and creatinine corrected by dividing the absolute cannabinoid value by the 
creatinine level. Temperature monitoring using a TempTrend (B) (Biosynergy Inc.) external thermometer tab adhered to the urine cup and creatinine determinations additionally served to detect attempts to alter urine samples via dilution. Typically, 3-4 days were required to meet the clean urine sample requirement following an active dose. Active doses were separated by at least five calendar days. After beginning the study, participation was discontinued following three drug-positive urine samples or breathalcohol samples. This requirement was used to rule out a potential interaction of acute marijuana and residual effects from extra-experimental drug use, including outside marijuana use. Three subjects were removed from the study for positive drug tests, all for marijuana and all before the initiation of active dosing.

\section{Apparatus}

During marijuana administration, subjects sat in a $1 \times 1 \mathrm{~m}^{2}$ chamber with two Plexiglas sides and an exhaust fan mounted at the top to ventilate smoke from the chamber. Inside the chamber were an ashtray, a pair of tweezers to hold the cigarette near the bottom, a cuff connecting to an oscillometric digital blood pressure (BP) and pulse monitor (Critikon Dynamap, Tampa, FL), and a carbon monoxide indicator (Vitalograph Inc., Lenexa, KS). One Plexiglas wall faced a computer video monitor used to cue events during the smoking protocol.

During experimental test sessions, subjects worked alone in a $1.2 \times 1.8 \mathrm{~m}^{2}$, sound-attenuating test chamber equipped with a $36.5 \mathrm{~cm}$ (14 in) VGA color monitor and a threebutton response panel. Experimental events and data collection were handled by a remote $(C)$ Microsoft Windows OS PC using custom software written in (C) Microsoft Visual Basic.

\section{Subject Payment and Schedule}

Subjects were paid daily for performance during experimental sessions, attendance, and clean urine samples, and were given a completion bonus at the end of the experiment. The testing protocol lasted 4 to 6 weeks, with subjects participating either 2 or 3 days per week, dictated by their schedules. During the first 2 days of the study, subjects were given an examination by a physician and provided initial exposure to the laboratory task (no marijuana doses were administered). The physical examination served to ensure subjects were free of any medical conditions that would preclude participation. Initial exposure to the task served to help stabilize performance prior to initiating dose administration.

Each day of the study, subjects arrived at approximately 0800 . Breath and urine samples were collected at $\approx 0815$. Subjects participated in four experimental sessions, each lasting $\approx 50 \mathrm{~min}$. The first testing session began at 0830 , prior to administration of the dose for that day. Following dose administration at 0945 , subjects completed three more test sessions at 1000,1300, and 1400. Between sessions, subjects stayed in a waiting room with magazines, books, and a TV. Lunch was provided at 1200. Subjects were not allowed to eat any other food or smoke cigarettes between 0800 and 1500. Compliance with nonsmoking instructions was verified by expired CO samples taken in the morning and afternoon.

\section{Marijuana Cigarettes and Administration}

Marijuana cigarettes supplied by NIDA were used and ranged across four doses: placebo cigarettes containing $0.0001 \%(\mathrm{w} / \mathrm{w}) \Delta^{9}$-THC; half of $1.77 \% \Delta^{9}$-THC (half placebo and half active cigarette, hereafter referred to as MJ1); $1.77 \%$ (both halves active, hereafter referred to as MJ2); and $3.89 \% \Delta^{9}$-THC (both halves active, hereafter referred to as $\mathrm{MJ} 3)$. Cigarettes were stored at $-20^{\circ} \mathrm{C}$ and cut in half and humidified before smoking. The purpose of dividing the cigarettes into two halves was to achieve a low dose (MJ1) sufficiently potent to produce a behavioral effect that was distinguishable from the intermediate and high doses. Subjects smoked the two cigarette halves immediately prior to the beginning of the second experimental session of the day (0945). Smoking was cued by a series of textual instructions, which appeared on the monitor screen: 'get ready' for $2 \mathrm{~s}$; 'inhale' for $3 \mathrm{~s}$; 'hold your breath' for $10 \mathrm{~s}$; and all lights off for $30 \mathrm{~s}$. The sequence repeated continuously until both halves of the cigarette were smoked.

Rather than hold constant the number of inhalations, all cigarette halves were smoked down to a pencil mark $\frac{1}{4}$ in from the end. In procedures that administer inhaled drugs, the following relevant parameters have been documented: drug concentration (eg THC content), inhalation volume, number of inhalations, and interinhalation interval (Azorlosa et al, 1995, 1992; Zacny et al, 1987). The procedure used here controlled for these parameters except for the number of inhalations, which was free to vary across subjects and doses, but was always recorded (see Table 1). Owing to individual differences in lung capacity and smoking history, inhalation volume typically varies across subjects. Here, volume was controlled as closely as possible by cueing the length of the inhalation with textual instructions. Subjects may compensate for THC content and the rapid psychoactive effects of high-potency THC by titrating inhalations at higher doses and thus require more inhalations to smoke an equivalent amount of the higher THC doses compared to placebo (Heishman et al, 1988; Kelly et al, 1993; Lane and Cherek, 2002). Thus, holding the number of inhalations constant across doses can result in differences in smoking volume (see Azorlosa et al, 1992). The number of inhalations per dose was recorded and compared across all conditions. Importantly, the current paced, cued smoking procedure has been widely used and produces reliable physiological and subjective effects data indicative of acute marijuana intoxication (Chait, 1989; Cherek et al, 2002; Haney et al, 1997; Lane and Cherek, 2002).

\section{Dosing Sequence}

Doses were administered in ascending order with intervening placebo doses preceding each active dose. An ascending sequence was chosen, as per the request of our local IRB, to minimize the possibility of side effects (eg anxiety in the testing chambers). This sequence also served to prevent large and unrecoverable changes in placebo/baseline levels of risk taking following the highest active marijuana dose, as placebo doses always were administered until the 
Table I Mean ( \pm SEM) Cardiovascular (Heart Rate=HR; Blood Pressure=BP; Carbon Monoxide= CO), Subjective (Questionnaire), and Behavioral (Inhalations, Response Rate, Risk Taking) Effects Related to the Effects of Marijuana Administration

\begin{tabular}{|c|c|c|c|c|c|}
\hline Dependent measure & Placebo & Half of $1.77 \%$ & $1.77 \%$ & $3.58 \%$ & F $(3,24), p$-value \\
\hline \multicolumn{6}{|l|}{ Administration data } \\
\hline$\Delta$ Heart rate & $+1.83(1.06)$ & $+8.70(3.79)$ & $+21.40(2.89)$ & $+31.90(4.65)$ & $22.38,<0.0001$ \\
\hline$\Delta$ Systolic BP & $-0.80(1.86)$ & $+7.60(3.75)$ & $+3.10(2.91)$ & $-2.40(4.88)$ & I.63, NS \\
\hline$\Delta$ Diastolic BP & $-2.73(1.28)$ & $+5.30(2.86)$ & $-1.20(2.46)$ & $-0.90(3.20)$ & $1.95, \mathrm{NS}$ \\
\hline CO boost & $+8.60(0.38)$ & $+8.60(0.90)$ & $+9.60(0.69)$ & $+9.20(0.65)$ & $2.01, \mathrm{NS}$ \\
\hline 'I feel dizzy, light-headed’ & $+0.50(0.13)$ & $+1.30(0.37)$ & $+1.80(0.44)$ & $+1.80(0.42)$ & $10.12,<0.0002$ \\
\hline 'I feel a typical marijuana high’ & $+1.20(0.19)$ & $+2.40(0.33)$ & $+3.20(3.27)$ & $+3.20(3.27)$ & $13.05,<0.0001$ \\
\hline \# of Inhalations & । $1.67(0.24)$ & $12.40(0.43)$ & I3.80 (0.36) & $13.10(0.48)$ & $5.78,<0.004 I$ \\
\hline
\end{tabular}

Values for HR, BR, CO, response rate (resp/s), and risky choices represent change scores (post- minus presmoking). The rightmost column shows the statistical outcomes (ANOVA) for each measure. Statistically significant results are shown in bold face type (all $\mathrm{df}=3,24)$. See text for further details on the statistical model and results.

behavioral performance data stabilized (stability criteria are discussed below). Therefore, multiple placebo doses were sometimes administered between active doses. For all analyses, only data from the stable placebo sessions that preceded the active doses are reported.

\section{Cardiovascular and Self-Report Measures}

Immediately prior to and following marijuana smoking, the subject's heart rate, systolic and diastolic BP, and breath carbon monoxide level were measured. Immediately after obtaining the postsmoking cardiovascular measures, subjects completed a rating form. They were asked to estimate the subjective effects of the marijuana cigarette on a fivepoint scale (anchored by ' 0 - not at all' and ' 4 - extremely') by rating the following statements: 'I feel an effect of the marijuana smoke', 'My heart is pounding faster than normal', 'I feel dizzy, lightheaded', and 'I feel a typical marijuana high'.

\section{Behavioral Measures}

Instructions. Prior to the first test session on day 1 , subjects were read a set of instructions regarding the risk-taking task. Each subject completed a 16-trial training session with eight forced exposures on each of the two response options; trial outcomes provided exposure to each outcome type (gain or loss), amount, and mimicked the exact probabilities used throughout the main experiment. Further details are provided in Lane et al (2004).

\section{Risk-Taking Task}

The task was designed to measure individual patterns of risk-taking behavior. This task has been used previously to measure acute alcohol effects on risk taking in humans
(Lane et al, 2004). The task presented discrete trials in which the subject was forced to choose between two response options, labeled $\mathrm{C}$ and $\mathrm{A}$ on the response panel. Displayed on screen at the beginning of each session were a counter at the top of the screen that showed an amount of money in dollars and cents, the letters $\mathrm{C}$ and A near the middle of the screen, and a question mark printed directly under the letter A. The counter at the top of the screen displayed $\$ 6.00$ on the first trial of every session, indicating to subjects that they were being given that amount of money to start the session. After the first trial, the counter was removed from the screen until the end of the session. Cumulative earnings were not displayed in order to increase the likelihood that each trial would function independently, anchored to a common baseline (see prospect theory, Kahneman and Tversky, 1979).

The task was a discrete-trial, two-choice procedure. Both response options had variable ratio (VR) 25 response requirements, meaning that on average 25 responses were required to complete each trial. Ratio values were generated and selected according to the Fleshler-Hoffman progression (Fleshler and Hoffman, 1962), an algorithm that produces a constant probability of reinforcement on any given response and responding that is generally rapid and consistent. The first press on either response button ( $\mathrm{C}$ or A) removed the nonselected letter from the monitor screen, indicating that the nonselected option was no longer available until the VR 25 had been completed on the selected option. The function of the VR 25 schedule was to assess drug effects on motor function via response rate. Completion of the VR 25 response requirement cleared all stimuli from the screen and then immediately showed the outcome of that trial for $5 \mathrm{~s}$ (see below). An intertrial interval (ITI) of $10 \mathrm{~s}$ separated each trial. The screen was blank during the ITI. Each session lasted 112 trials. The $10 \mathrm{~s}$ ITI functioned both to promote independence of each trial 
and to extend session length (approximately $50 \mathrm{~min}$ ) in order to capture peak effects of marijuana intoxication.

\section{Payoff Contingencies}

The C option was designated as 'nonrisky'. Selection of the nonrisky option produced a gain of $\$ 0.01$ at a probability of 1.0. The gain amount was printed at the top of the screen in green for $5 \mathrm{~s}$ as ' $+\$ 0.01$ '. Thus, the net outcome (ie expected value or amount $\times$ probability) of selecting the nonrisky option was $\$ 1.12$, thereby $\$ 7.12$ total for the session. The A option was designated as 'risky'. Selection of the risky option delivered either a gain or a loss of $\$ 0.25$, $\$ 0.50, \$ 0.75$, or $\$ 1.00$. The probability of gain/loss was 0.50 . Outcomes were printed in green and preceded by ' $+\$$ (gains) or in red and preceded by '- \$' (losses). All four monetary amounts were equiprobable on each trail and outcome probabilities were random and stochastic. Thus, the net outcome (ie expected value) of selecting the risky option was $\$ 0$, thereby producing an average of $\$ 6.00$ total for the session. Over many trials, the risky option was therefore the less adaptive choice. However, since outcome probabilities were stochastic, in a 112-trial session choosing option A on every trial could produce either gains or losses of up to approximately $\$ 9.00$. Thus, the task was also designed to measure individuals' tolerance for large gains and losses as a result of risk taking. Indeed, it was possible to finish individual sessions with a negative value. However, due to the equal gain-loss probabilities and the starting value of $\$ 6.00$, all subjects finished all experimental days with positive earnings.

\section{Psychometric Measures}

On the final day of participation, subjects were administered several questionnaires to measure aspects of impulsiveness, risk taking, and cognitive function. Impulsiveness was measured by the Eysenck Impulsivity and Venturesomeness Questionnaire (EIVQ, Eysenck and Eysenk, 1978) and the Barratt Impulsivity Scale (BIS-11, Patton et al, 1995). Risk taking was measured by the EIVQ, the Zuckerman Sensation Seeking Scale (SSS, Zuckerman, 1979), and the Cognitive Appraisal of Risky Events (CARE, Fromme et al, 1997). The CARE assessed subjects' recent risk-taking behavior by asking about the frequency of a number of risky behaviors (drug use, fighting, DWI, unprotected sex) engaged in over the past 6 months. To assess cognitive functioning, all subjects were administered the Shipley Institute of Living Scale (Shipley-Boyle, 1967), a test of general intellectual aptitude that includes a 40-item vocabulary test and a 20 -item abstraction test. Shipley score estimates of WAIS IQ correlate highly (0.76-0.87) with actual WAIS IQ scores (Zachary et al, 1985). The average age-adjusted Shipley $t$-score was $50.40( \pm 4.74)$. Psychometric data were used as supplemental measures of subjects' psychological profiles, and for general comparisons with the behavioral data.

\section{Dependent Measures and Stability Criteria}

The dependent measure for stability calculations was the mean number of risky choices per session. Stability criteria included both visual inspection and the coefficient of variation across the four test sessions (standard deviation/ mean, see Snedecor and Cochran, 1980), which had to be below 0.25 . Most subjects met the stability criteria on the first day; others met the criteria by the end of the first placebo administration.

The primary dependent variable of interest was the number of choices for the risky option (the A button). Other dependent measures of behavior included overall response rate and an analysis of trial-by-trial response probabilities (described below). Risk-taking patterns and response rates during Session 1 often varied across experimental days, but were stable within experimental days. As a result, behavioral data were calculated as a difference score between Session 1 (preadministration) and Session 2 (immediately following marijuana administration, during peak effects). The onset of acute subjective, biological, and behavioral effects of smoked marijuana occurs within $5 \mathrm{~min}$ of smoking (Azorlosa et al, 1995; Huestis et al, 1992) and the acute behavioral effects typically last no more than $2 \mathrm{~h}$ (see Chait and Pierri, 1992 for a review). Test sessions 3 and 4 occurred at 3 and $4 \mathrm{~h}$ postsmoking, and following acute doses these sessions were often marked by highly unsystematic variability in performance. We could not attribute this variability to acute marijuana intoxication and, as is typical in laboratory marijuana studies, limited our analyses to peak effects $0-60 \mathrm{~min}$ after smoking.

\section{Data Analyses}

Statistical analyses of all dependent measures (behavioral, subjective, and cardiovascular) employed a multivariate mixed-model ANOVA with a between-subjects factor of gender and repeated measures across dose. As this study employed an ascending dose sequence, an additional repeated-measures ANOVA was conducted to evaluate performance across the three placebo administrations. This analysis served to assess possible systematic shifts in risk-taking performance, subjective effects, or smoking topography over the course of the study, which might influence the data analyses. Tukey's HSD post hoc comparisons were used to examine significant main effects and interactions. Statistical analyses were performed using SAS Proc GLM (c) SAS, Cary, NC).

To assess risk-taking patterns with regard to reinforcing and aversive consequences, an analysis of trial-by-trial response probabilities was conducted. Response data from Session 2 were collapsed across subjects and submitted to a first-order Markov process analysis using UNCERT software (Hailman and Hailman, 1993). The analysis provides a matrix of all possible two-event transition probabilities. In the present case, three event types were possible: nonrisk, risk + gain, and risk + lose, resulting in a $3 \times 3$ transition matrix. The resulting matrices for each dose were analyzed graphically and statistically via the Mantel-Haenszel test, a variation of the $\chi^{2}$ procedure appropriate for contingency tables greater than $2 \times 2$ (Stokes et al, 2000). The MantelHaenszel tests provided an evaluation of whether the $3 \times 3$ transition-probability matrices were statistically different, and if so, which type of event transitions were unique between the doses. This analysis provided an indication of 
sensitivity, or reactivity, to the decision-making outcomes (risky and nonrisky). Statistical analyses were performed using SAS Proc FREQ.

\section{RESULTS}

\section{Marijuana Administration}

Table 1 shows data from the marijuana administration procedure at each dose, including the cardiovascular and subjective effects, breath $\mathrm{CO}$ change, number of inhalations, response rate change, and change in the number of risky choices. Table 1 also summarizes which measures revealed significant main effects of dose and the corresponding F-value and $p$-value. The cardiovascular, $\mathrm{CO}$ boost, and subjective effects data serve to document and replicate the well-known physiological and subjective effects of smoking marijuana (Azorlosa et al, 1995; Huestis et al, 1992).

Marijuana produced a significant increase in heart rate change from pre- to postsmoking, $p<0.0001$. Tukey's HSD tests $(\alpha=0.01)$ showed that heart rate changes at the MJ2 and MJ3 doses were greater than placebo, and the MJ3 dose heart rate change was greater than the MJ1 dose. Heart rate increase is among the most reliable, dose-related indicators of acute marijuana administration. There were no significant effects on any measure of systolic or diastolic BP or CO boost.

Marijuana significantly increased subjective ratings on all four questions. The significant main effects were as follows: Question 1, 'I feel an effect of marijuana smoke', $p<0.0001$; Question 2, 'My heart is pounding faster than normal', $p<0.003$; Question 3, 'I feel dizzy, light-headed', $p<0.0002$; and Question 4, 'I feel a typical marijuana high', $p<0.0001$ (see Table 1 for details). For all four questions, Tukey's HSD tests revealed the same pattern: scores at the MJ2 and MJ3 doses were greater than placebo, with $\alpha=0.05$ for Questions 1 and 2 and $\alpha=0.01$ for Questions 3 and 4 . There were no effects of gender or dose $\times$ gender interactions.

The number of inhalations increased as function of dose, $p<0.004$. Tukey's post hoc tests $(\alpha=0.05)$ showed the number of inhalations at both MJ2 and MJ3 to be greater than placebo. This implies that subjects titrated their smoke intake at the intermediate (MJ2, 1.77\% THC) and high (MJ3, $3.58 \% \mathrm{THC}$ ) doses and required roughly 1.4 to 2.1 extra inhalations to smoke an equivalent amount of marijuana. Titration has been observed in previous studies, and is attributed to subject's rapid discrimination of the psychoactive effects of the high THC-content marijuana (Heishman et al, 1988; Kelly et al, 1993; Lane and Cherek, 2002).

Marijuana did not significantly alter response rates, but there was a significant effect of gender on response rate, $\mathrm{F}(1,8)=23.41, p<0.0001$. Tukey's post hoc tests $(\alpha=0.05)$ showed that men had a larger increase in response rate than women following marijuana administration at the MJ1 and MJ2 doses. The main effect of gender reflects both higher baseline response rates in men and perhaps differential stimulation of the MJ1 and MJ2 doses between men and women.

Analysis of only the three placebo administrations revealed that there were no effects, indicating that the ascending dose sequence did not systematically affect any of the measures.

\section{Risk-Taking Data}

Figure 1 and Table 1 (bottom) show the effect of placebo and the three marijuana doses on the risky response data, calculated as the difference score between the number of risky choices in Session 2 (peak effect) and Session 1 (predose). Marijuana significantly increased risky responding, $\mathrm{F}(3,24)=3.42, p<0.033$. Tukey's post hoc tests $(\alpha=0.05)$ revealed just one significant difference: the increase in risk taking following the MJ3 dose (3.58\% THC) was greater than placebo.

Figure 2 shows the first-order Markov transition probabilities for the placebo and MJ3 data. In the $3 \times 3$ matrix, each bar represents a transition between any two events at trial $N$ and trial $N+1$. For example, the bottom rightmost bars $(R+G / R+G)$ show the probability of two consecutive risky responses that resulted in a gain of money. The figure makes clear that transition probabilities were highly similar between the placebo and MJ3 doses when trial $N$ was a nonrisky response (NR), but changed significantly when trial $N$ was risky response. Examining both types of risky outcomes $(\mathrm{R}+\mathrm{G}$ and $\mathrm{R}+\mathrm{L})$ together, it is apparent that following the MJ3 dose, subjects were more likely to persist on the risky option, whether winning or losing. Notably, the largest between-dose discrepancies were observed following a risky response that resulted in a loss of money $(\mathrm{R}+\mathrm{L})$. Under placebo, subjects were most likely to shift to the NR option. The probability of this shift away from the risky option was much lower under the MJ3 dose. These patterns were supported by the statistical analyses. The General Association statistic from the Mantel-Haenszel test was $Q_{\mathrm{HM}}(2)=17.44, \quad p<0.0001$, revealing that the overall transition probability distributions were significantly different between the placebo and MJ3 doses. Individual row

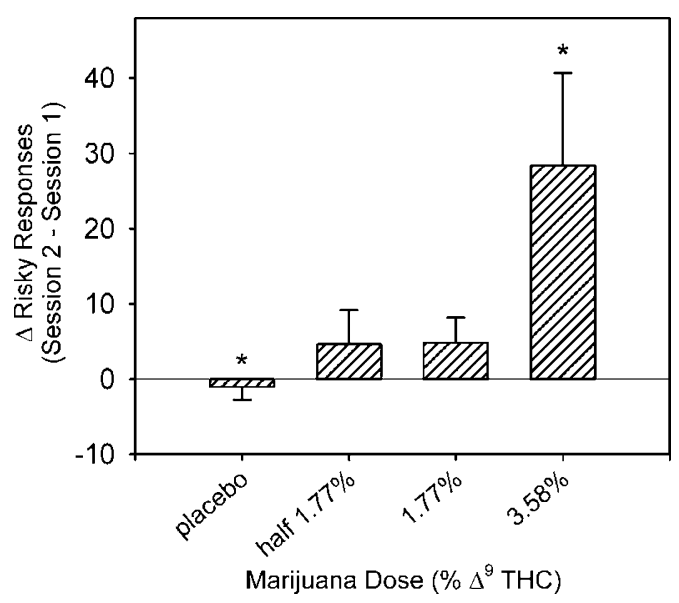

Figure I Change in risky responses from Session I (predose) to Session 2 (peak effect) across placebo and three doses of marijuana. Change scores were calculated as the number of risky responses in Session 2 minus number of risky responses in Session I. Each bar represents the mean \pm I SEM; bars above 0 show an increase in risk taking and bars below show a decrease. Asterisks show doses that were statistically different. 


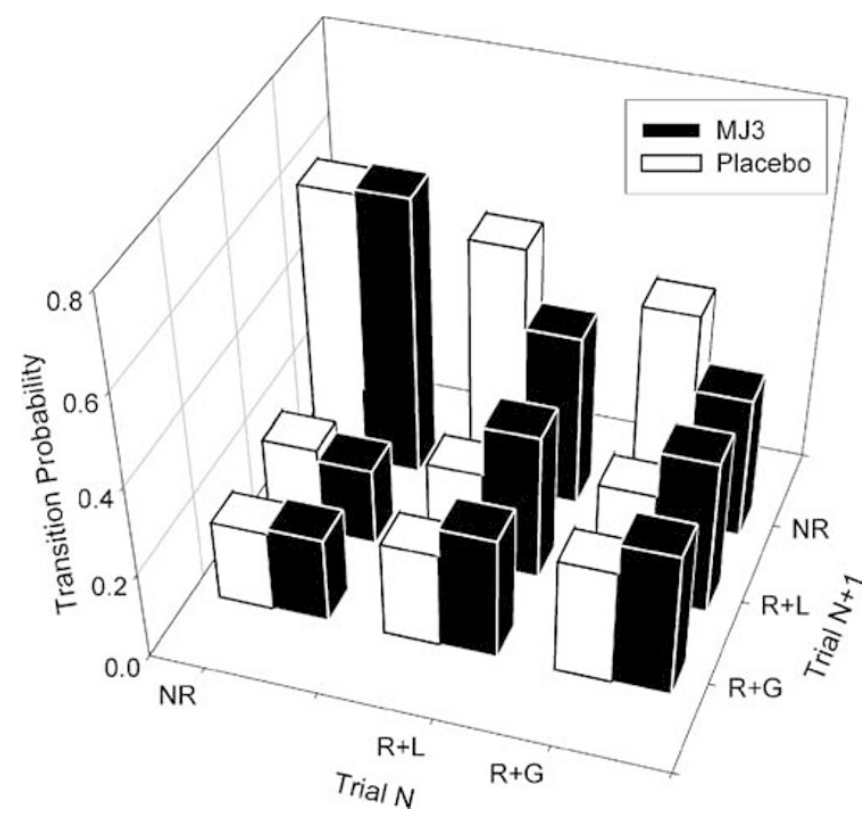

Figure 2 First-order Markov transition probabilities for the placebo and MJ3 data derived from the individual trial data. The data from Session 2 (peak effect, immediately after marijuana smoking) were collapsed across all subjects. The $3 \times 3$ matrix shows all possible two-event transition probabilities. Each bar represents a transition between any two events at trial $N$ and trial $N+$ I (eg bottom rightmost bars, $R+G / R+G$, show the probability of two consecutive risk + gain trials). Transition probabilities were highly similar between the placebo and MJ3 doses when trial $N$ was an NR, but changed significantly when trial $N$ was a reinforced or losing risky response. Following the $\mathrm{MJ} 3$ dose, subjects were more likely to persist on the risky option, whether winning or losing. These patterns were supported by the statistical analyses via the General Association statistic from the Mantel-Haenszel test. See text for details.

by column analyses showed no difference between the doses in transitions from nonrisky choices, $Q_{\text {HмСS }}(1)=0.75$, NS. Both transitions from reinforced- and losing-risky trials were statistically different between the doses: for $\mathrm{R}+\mathrm{L}$, $Q_{\text {HMCS }}(1)=21.74, p<0.0001$; for $\mathrm{R}+\mathrm{G}, Q_{\text {HмCS }}(1)=15.39$, $p<0.0001$.

Comparisons of the (a) psychometric data, and (b) physiological, subjective effects, and inhalation data with the risk-taking data were employed to evaluate the possibility that one or more of these measures would be predictive of THC-related increases in risk taking. To that end, a series of multiple linear regression analyses were conducted with the increase in risky choices at the MJ3 dose as the dependent variable, regressed against (a) all psychometric measures and (b) all marijuana administration measures. None of the regression analyses revealed a significant outcome, and no individual test or combination of tests was a significant predictor of risk taking at the MJ3 dose (all $p$-values $>0.20$ ). A backward stepwise regression that retained a combination of $\mathrm{CO}$ boost, heart rate change, and number of inhalations revealed an $r$-squared value of $0.65, \mathrm{~F}=3.7, p=0.08$. This trend suggests that subjects with stronger and deeper inhalation topographies showed a larger increase in risk taking at the MJ3 dose. The failure to find a significant relationship between the psychometric (personality) measures and the effects of THC on risky decision making may be due to the sample size of 10 . Future studies seeking to uncover such relationships will require greater power with a larger cohort.

\section{DISCUSSION}

Marijuana use is related to a number of risky behaviors that may result in aversive consequences to self or others, including crime, other drug use, risky driving, traffic accidents, and high-risk sexual activity (Brook et al, 1999; Cunningham et al, 2000; Friedman et al, 2001; Kingree et al, 2000). Despite the relationship between marijuana use and maladaptive risky behavior, few laboratory studies have investigated the relationship between marijuana intoxication and risk taking (Janowsky et al, 1976; Liguori et al, 1998; and Ramaekers et al, 2000 showed impaired riskrelated performance on driving/flying simulators). The present study utilized a within-subject repeated-measures design and a two-choice laboratory task developed to examine acute drug effects on risk taking. Choices for the response option operationally defined as risky were significantly increased at the highest dose $\left(3.58 \% \Delta^{9}\right.$ THC). In addition, this dose altered sensitivity to reinforcing and aversive outcomes as measured via changes in trial-by-trial response probabilities, suggesting a possible mechanism by which psychoactive drugs may influence risk-taking behavior.

Significant differences in the number of inhalations required to smoke the cigarettes were observed across doses. Most notably, subjects required more inhalations to smoke the 1.77 and $3.58 \%$ cigarettes compared to placebo. Despite attempts to control inhalation volume via discriminative cues, titration of smoke volume is regularly observed in studies administering smoked marijuana to humans (Heishman et al, 1989; Kelly et al, 1993; Lane and Cherek, 2002). As $\Delta^{9}$-THC content increases, subjects typically reduce the strength of inhalations presumably to control the rapid onset of psychoactive effects that follow smoking high THC-content marijuana. Despite this outcome, measures of heart rate and subjective effects reliably increased as a function of THC content, and the CO boost levels were not significantly different. These data suggest that the total smoke intake was similar across doses, and that the administration procedures had the intended doserelated effect. Specifically, requiring subjects to smoke each cigarette half down to the $\frac{1}{4}$ in mark engendered equivalent smoke intake at each dose despite titration. Requiring subjects to take the same number of inhalations at each dose may have produced uncontrolled variance in smoke intake as a result of titration.

The increase in risk taking observed at the 3.58\% THC dose supports epidemiological evidence, indicating that risky behavior may be related to the level or chronicity of marijuana use (Brook et al, 1999; Malow et al, 2001; Ramaekers et al, 2004). Previous laboratory studies of acute marijuana effects on aggression (Cherek et al, 1993), response inhibition (McDonald et al, 2003), risky driving maneuvers (Liguori et al, 1998), and complex decision making (Curran et al, 2002) collectively suggest that marijuana may engender disinhibition at doses sufficient to produce a state of intoxication. In the present study, it is possible that the effect on risk taking was observed only 
with the 3.58\% THC cigarette because only this dose created a requisite level of impairment to disrupt inhibitory processes. Impairment in inhibitory processes provides a possible mechanism through which marijuana may influence risky decision making.

THC-induced disruption of the mesolimbic-prefrontal cortical (PFC) network, and a related change in behavioral sensitivity to consequences, may be related to the observed risk-taking patterns. Previous neuroimaging studies of human risky decision making have identified brain structures that function in the evaluation and anticipation of risky and/or uncertain response options; these include mesolimbic, limbic, and specific PFC regions (Bechara et al, 1999; Bechara et al, 2003; Breiter et al, 2001; Ernst et al, 2002, Matthews et al, 2004; Paulus et al, 2001, Rogers et al, 1999). Importantly, $\Delta^{9}$-THC impacts neurotransmission in several of these same areas (Iversen, 2003; Gardner and Vorel, 1998; O'Leary et al, 2002). Previous work also suggests that differential sensitivity to reward and punishment is related to individual differences in risk taking (Bechara et al, 2002; Lane and Cherek, 2000; Lane et al, 2004; Rogers et al, 2003). The observed shift in response probabilities following reinforcing (winning) and aversive (losing) outcomes shown in Figure 2 is consistent at a behavioral level with the aforementioned findings. Specifically, the trial-by-trial data suggest that the increase in risk taking at the highest dose was related to a reorganization of behavior with regard to both reinforced and losing risky trials. Subjects perseverated on the risky option significantly more than under placebo conditions. We interpret this change as indicating differential sensitivity to rewards and losses, a change that was also observed following alcohol administration (Lane et al, 2004). Acute marijuana administration may affect both mesolimbic-PFC activity and sensitivity to consequences - both of which are involved in risk taking/decision making (Bechara et al, 2003; Breiter et al, 2001; Rogers et al, 2003; see also Lane and Cherek, 2002)-providing a potential mechanism through which marijuana might engender changes in risky behavior.

In the absence of more direct neurobiological and behavioral data, the assumptions about THC-related changes in risk taking should be seen as preliminary, and confirmation will require further experimentation. Indeed, determining the acute effects of $\Delta^{9}$-THC on (a) reinforced and punished behavior and (b) the interaction with specific biobehavioral processes that mediate response to reinforcing and aversive consequences may be an important direction for future studies seeking to understand the relationship between marijuana and risk taking.

\section{ACKNOWLEDGEMENTS}

This research was supported by NIDA Grants DA R01 15392 (SDL) and DA R01 12968 (SDL). We wish to thank Dr Kim Fromme for generously providing psychometric instruments, and Dr Joel L Steinberg, Sheila White, Jennifer Sharon, Sally Chee, and Laurie Thompson for their valuable contributions to this project. We have no conflicts of interest to report.

\section{REFERENCES}

Adlaf EM, Smart RG (1983). Risk-taking and drug-use behaviour: an examination. Drug Alcohol Depend 11: 287-296.

Azorlosa JL, Greenwald MK, Stitzer ML (1995). Marijuana smoking: effects of varying puff volume and breathhold duration. J Pharmacol Exp Ther 272: 560-569.

Azorlosa JL, Heishman SJ, Stitzer ML, Mahaffey JM (1992). Marijuana smoking: effect of varying delta 9-tetrahydrocannabinol content and number of puffs. J Pharmacol Exp Ther 261: 114-122.

Bechara A, Damasio H, Damasio AR (2003). Role of the amygdala in decision-making. Ann NY Acad Sci 985: 356-369.

Bechara A, Damasio H, Damasio AR, Lee GP (1999). Different contributions of the human amygdala and ventromedial prefrontal cortex to decision making. J Neurosci 19: 5473-5481.

Bechara A, Dolan S, Hindes A (2002). Decision-making and addiction (part II): myopia for the future or hypersensitivity to reward? Neuropsychologia 40: 1690-1705.

Breiter HC, Aharon I, Kahneman D, Dale A, Shizgal P (2001). Functional imaging of neural responses to expectancy and experience of monetary gains and losses. Neuron 30: 619-639.

Brook JS, Balka EB, Whiteman M (1999). The risks for late adolescence of early adolescent marijuana use. Am J Public Health 89: 1549-1554.

Brookoff D, Cook CS, Williams C, Mann CS (1994). Testing reckless drivers for cocaine and marijuana. $N$ Engl J Med 331: $518-522$

Byrnes JP (1998). The Nature and Development of Decision Making. Lawrence Erlbaum Associates: Hillsdale, NJ.

Chait LD (1989). Delta-9-tetrahydrocannabinol content and human marijuana self- administration. Psychopharmacol 98: 51-55.

Chait LD, Pierri J (1992). Effects of smoked marijuana on human performance: A critical review. In: Murphy LL, Bartke A (eds). Marijuana/Cannabinoids: Neurobiology and Neurophysiology. CRC Press: Boca Raton, FL. pp 387-423.

Cherek DR, Lane SD, Dougherty DM (2002). Possible amotivational effects following marijuana smoking under laboratory conditions. Exp Clin Psychopharmacol 10: 26-38.

Cherek DR, Roache JD, Egli M, Davis C, Spiga R, Cowan K (1993). Acute effects of marijuana smoking on aggressive, escape and point-maintained responding of male drug-users. Psychopharmacol 111: 163-168.

Cunningham JA, Bondy SJ, Walsh GW (2000). The risks of cannabis use: evidence of a dose-response relationship. Drug Alc Rev 19: 137-142.

Curran HV, Brignell C, Fletcher S, Middleton P, Henry J (2002). Cognitive and subjective dose-response effects of acute oral Delta 9-tetrahydrocannabinol (THC) in infrequent cannabis users. Psychopharmacol 164: 61-70.

Duncan SC, Strycker LA, Duncan TE (1999). Exploring associations in developmental trends of adolescent substance use and risky sexual behavior in a high-risk population. J Behav Med 22: 21-34.

Ernst M, Bolla K, Mouratidis M, Contoreggi C, Matochik JA, Kurian V et al (2002). Decision-making in a risk-taking task: a PET study. Neuropsychopharmacol 26: 682-691.

Eysenck SB, Eysenck HJ (1978). Impulsiveness and venturesomeness: Their position in a dimensional system of personality description. Psychol Rep 43: 1247-1255.

Fergusson DM, Horwood LJ (1997). Early onset cannabis use and psychosocial adjustment in young adults. Addiction 92: 279-296.

First MB, Spitzer RL, Gibbon M, Williams JBW (1996). Structured Clinical Interview for DSM-IV Axis I Disorders: Non patient edition (SCID-NP), 20 edn. NY State Psychiatric Institute: New York.

Fleshler M, Hoffman HS (1962). A progression for generating variable-interval schedules. J Exp Anal Behav 5: 529-530. 
Foltin RW, Fischman MW, Brady JV, Kelly TH, Bernstein DJ, Nellis MJ (1989). Motivational effects of smoked marijuana: behavioral contingencies and high-probability recreational activities. Pharmacol Biochem Behav 34: 871-877.

Friedman AS, Glassman K, Terras A (2001). Violent behavior as related to use of marijuana and other drugs. J Addic Dis 20: 49-72.

Fromme K, Katz E, D'Amico E (1997). Effects of alcohol intoxication on the perceived consequences of risk taking. Exp Clin Psychopharm 5: 14-23.

Galbicka G, Lee DM, Branch MN (1980). Schedule-dependent tolerance to behavioral effects of delta 9-tetrahydrocannabinol when reinforcement frequencies are matched. Pharmacol Biochem Behav 12: 85-91.

Gardner EL, Vorel SR (1998). Cannabinoid transmission and reward-related events. Neurobiol Dis 5: 502-533.

Hailman ED, Hailman JP (1993). UNCERT: analysis of sequential events by Markov chains. Computer Archives for the Study of Animal Behavior (CASAB). http://www.animalbehavior.org/ Resources/CSASAB/.

Haney M, Comer SD, Ward AS, Foltin RW, Fischman MW (1997). Factors influencing marijuana self-administration by humans. Behav Pharmacol 8: 101-112.

Hansteen RW, Miller RD, Lonero L, Reid LD, Jones B (1976). Effects of cannabis and alcohol on automobile driving and psychomotor tracking. Ann NY Acad Sci 282: 240-256.

Hastie R, Dawes RM (2001). Rational choice in an uncertain world: The psychology of judgement and decision making. Sage: Thousand Oaks, CA.

Heishman SJ, Stitzer ML, Bigelow GE (1988). Alcohol and marijuana: comparative dose effect profiles in humans. Pharmacol Biochem Behav 31: 649-655.

Heishman SJ, Stitzer ML, Yingling JE (1989). Effects of tetrahydrocannabinol content on marijuana smoking behavior, subjective reports, and performance. Pharmacol Biochem Behav 34: 173-179.

Huestis MA, Henningfield JE, Cone EJ (1992). Blood cannabinoids. I. Absorption of THC and formation of 11-OH-THC and THCCOOH during and after smoking marijuana. J Anal Toxicol 16: $276-282$.

Iversen L (2003). Cannabis and the brain. Brain 126: 1252-1270.

Janowsky DS, Meacham MP, Blaine JD, Schoor M, Bozzetti LP (1976). Marijuana effects on simulated flying ability. $\mathrm{Am}$ J Psychiatry 133: 384-388.

Kahneman D, Tversky A (1979). Prospect theory-analysis of decision under risk. Econometrica 47: 263-291.

Kahneman D, Tversky A (1984). Choices, values, and frames. Am Psychol 39: 341-350.

Kelly TH, Foltin RW, Fischman MW (1993). Effects of smoked marijuana on heart rate, drug ratings, and task performance by humans. Behav Pharmacol 4: 167-178.

Kingree JB, Betz H (2003). Risky sexual behavior in relation to marijuana and alcohol use among African-American, male adolescent detainees and their female partners. Drug Alc Depend 72: 197-203.

Kingree JB, Braithwaite R, Woodring T (2000). Unprotected sex as a function of alcohol and marijuana use among adolescent detainees. J Adol Health 27: 179-185.

Lane SD, Cherek DR (2000). Analysis of risk taking in adults with a history of high risk behavior. Drug Alc Depend 60: 179-187.

Lane SD, Cherek DR (2001). Risk taking by adolescents with maladaptive behavior histories. Exp Clin Psychopharmacol 9: $74-82$.

Lane SD, Cherek DR (2002). Marijuana effects on sensitivity to reinforcement in humans. Neuropsychopharmacology 26: 520-529.

Lane SD, Cherek DR, Pietras CJ, Tcheremissine OV (2004). Alcohol effects on human risk taking. Psychopharmacologia 172: 68-77.
Liguori A, Gatto CP, Jarrett DB (2002). Separate and combined effects of marijuana and alcohol on mood, equilibrium and simulated driving. Psychopharmacologia 163: 399-405.

Liguori A, Gatto CP, Robinson JH (1998). Effects of marijuana on equilibrium, psychomotor performance, and simulated driving. Behav Pharmacol 9: 599-609.

Loeber RT, Yurgelun-Todd DA (1999). Human neuroimaging of acute and chronic marijuana use: Implications for frontocerebellar dysfunction. Hum Psychopharmacol Clin Exp 14: 291-304.

Lopes LL (1987). Between fear and hope: The psychology of risk. In: Berkowitz L (ed). Advances in Experimental Social Psychology. Academic Press: New York. pp 255-295.

Luce RD (1967). Games and Decisions. Wiley: New York.

Malow RM, Devieux JG, Jennings T, Lucenko BA, Kalichman SC (2001). Substance-abusing adolescents at varying levels of HIV risk: Psychosocial characteristics, drug use, and sexual behavior. J Subst Abuse 13: 103-117.

Matthews SC, Simmons AN, Lane SD, Paulus MP (2004). Selective activation of the nucleus accumbens during risk-taking decision making. Neuroreport 15: 2123-2127.

McDonald J, Schleifer L, Richards JB, de Wit H (2003). Effects of THC on behavioral measures of impulsivity in humans. Neuropsychopharmacology 28: 1356-1365.

Miller DC, Byrnes JP (1997). The role of contextual factors and personal factors in children's risk taking. Dev Psychol 33: 814-823.

Moskowitz H (1985). Marijuana and driving. Accident Anal Prev 17: 323-345.

O'Leary DS, Block RI, Koeppel JA, Flaum M, Schultz SK, Andreasen NC et al (2002). Effects of smoking marijuana on brain perfusion and cognition. Neuropsychopharmacology 26 802-816.

Patton JH, Stanford MS, Barratt ES (1995). Factor structure of the Barratt Impulsiveness Scale. J Clin Psychol 51: 768-774.

Paulus MP, Hozack N, Zauscher B, McDowell JE, Frank L, Brown GG et al (2001). Prefrontal, parietal, and temporal cortex networks underlie decision-making in the presence of uncertainty. Neuroimage 13: 91-100.

Pihl RO, Sigal H (1978). Motivation levels and the marijuana high. J Abnorm Psychol 87: 280-285.

Pistis M, Ferraro L, Pira L, Flore G, Tanganelli S, Gessa GL et al (2002). Delta(9)-tetrahydrocannabinol decreases extracellular GABA and increases extracellular glutamate and dopamine levels in the rat prefrontal cortex: an in vivo microdialysis study. Brain Res 948: 155-158.

Rachlin H (1990). Why do people gamble and keep gambling despite heavy losses? Psychol Sci 1: 294-297.

Rachlin H, Logue AW, Gibbon J, Frankel M (1986). Cognition and behavior in studies of choice. Psychol Rev 93: 33-45.

Ramaekers JG, Berghaus G, van Laar M, Drummer OH (2004). Dose related risk of motor vehicle crashes after cannabis use. Drug Alcohol Depend 73: 109-119.

Ramaekers JG, Robbe HW, O'Hanlon JF (2000). Marijuana, alcohol and actual driving performance. Hum Psychopharmacol 15: $551-558$.

Rogers RD, Owen AM, Middleton HC, Williams EJ, Pickard JD, Sahakian BJ et al (1999). Choosing between small, likely rewards and large, unlikely rewards activates inferior and orbital prefrontal cortex. J Neurosci 19: 9029-9038.

Rogers RD, Tunbridge EM, Bhagwagar Z, Drevets WC, Sahakian BJ, Carter CS (2003). Tryptophan depletion alters the decision-making of healthy volunteers through altered processing of reward cues. Neuropsychopharmacology 28: 153-162.

Schaefer CF, Gunn CG, Dubowski KM (1977). Dose-related heartrate, perceptual, and decisional changes in man following marijuana smoking. Percept Motor Skills 44: 3-16. 
Schulze GE, McMillan DE, Bailey JR, Scallet AC, Ali SF, Slikker Jr $\mathrm{W}$ et al (1989). Acute effects of marijuana smoke on complex operant behavior in rhesus monkeys. Life Sci 45: 465-475.

Shafir E, Tversky A (1995). Decision making. In: Smith EE, Osherson DN (eds). Thinking: An Invitation to Cognitive Science. MIT Press: Cambridge, MA. pp 77-100.

Shipley-Boyle B (1967). The Shipley Institute of Living Scale. Western Psychological Services: Los Angeles, CA.

Slovic P (1969). Differential effects of real versus hypothetical payoffs on choices among gambles. J Exp Psychol 80: 434-437.

Snedecor GW, Cochran WG (1980). Statistical Methods, 7th edn. The Iowa State University Press: Ames, IA.

Soderstrom CA, Dischinger PC, Kerns TJ, Trifillis AL (1995). Marijuana and other drug-use among automobile and motorcyle drivers treated at a trauma center. Accident Anal Prev 27: 131-135.

Staton M, Leukefeld C, Logan TK, Zimmerman R, Lynam D, Milich $\mathrm{R}$ et al (1999). Risky sex behavior and substance use among young adults. Health Soc Work 24: 147-154.

Stoduto G, Vingilis E, Kapur BM, Sheu WJ, Mclellan BA, Liban CB (1993). Alcohol and drug use among motor-vehicle collision victims admitted to a regional trauma unit-demographic, injury, and crash characteristics. Accident Anal Prev 25: 411-420.

Stokes ME, Davis CS, Koch GG (2000). Categorical Data Analysis Using the SAS System, 2nd edn. SAS Institute: Cary, NC.
Tanda G, Goldberg SR (2003). Cannabinoids: reward, dependence, and underlying neurochemical mechanisms - a review of recent preclinical data. Psychopharmacologia 169: 115-134.

Tanda G, Pontieri FE, Di Chiara G (1997). Cannabinoid and heroin activation of mesolimbic dopamine transmission by a common mul opioid receptor mechanism. Science 276: 2048-2050.

Volkow ND, Gillespie H, Mullani N, Tancredi L, Grant C, Valentine A et al (1996). Brain glucose metabolism in chronic marijuana users at baseline and during marijuana intoxication. Psychiatry Res 67: 29-38.

Walsh GW, Mann RE (1999). On the high road: driving under the influence of cannabis in Ontario. Can J Public Health 90: 260-263.

Watts WD, Wright LS (1990). The relationship of alcohol, tobacco, marijuana, and other illegal drug use to delinquency among Mexican-American, Black, and White adolescent males. Adolescence 25: 171-181.

White HR (1991). Marijuana use and delinquency - a test of the independent cause hypothesis. J Drug Issues 21: 231-256.

Zachary RA, Paulson MJ, Gorsuch RL (1985). Estimating WAIS IQ from the Shipley Institute of Living Scale using continuously adjusted age norms. J Clin Psychol 41: 820-831.

Zacny JP, Stitzer ML, Brown FJ, Yingling JE, Griffiths RR (1987). Human cigarette smoking: effects of puff and inhalation parameters on smoke exposure. J Pharmacol Exp Ther 240: 554-564.

Zuckerman M (1979). Sensation Seeking: Beyond the Optimal Level of Arousal. Lawrence Erlbaum Associates: Hillsdale, NJ. 